\title{
Striking Down Barriers: Parents' Perspectives of Youth Sport Programs for Their Children with Disabilities
}

\author{
Sara E. Corning, Caroline J. Ketcham*, Eric E. Hall \\ Department of Exercise Science, Elon University, Elon, NC, USA \\ Email: *cketcham@elon.edu
}

How to cite this paper: Corning, S. E., Ketcham, C. J., \& Hall, E. E. (2020). Striking Down Barriers: Parents' Perspectives of Youth Sport Programs for Their Children with Disabilities. Advances in Physical Education, 10, 459-475

https://doi.org/10.4236/ape.2020.104036

Received: September 3, 2020

Accepted: November 16, 2020

Published: November 19, 2020

Copyright $\odot 2020$ by author(s) and Scientific Research Publishing Inc. This work is licensed under the Creative Commons Attribution International License (CC BY 4.0).

http://creativecommons.org/licenses/by/4.0/

\begin{abstract}
Participation in sports provides opportunity for children to improve cognitively, physically, and socially. The purpose of this study was to explore family experiences and expectations in sport experiences specifically targeted to children with disabilities, and the relationship to volunteer/coach training. An online questionnaire was distributed to parents with children in these sport experiences $(n=56)$. Measures of quality of life were included as well as open-ended questions around motivation to join programs, expectations, challenges, role volunteers/coaches play, and barriers of program involvement for their child and family. Results showed that family quality of life and well-being on the pediatric quality of life inventory were both significantly lower for children with multiple disabilities compared to one disability $(p<$ $0.05)$. Qualitative analyses suggest improving aspects such as organizational structure of sport programs, accessibility, volunteer/coach training, and ensuring appropriate accommodations to improve inclusion of children. These recommendations could be implemented to benefit not only the children with disabilities and their families, but all participants involved in youth sport programs.
\end{abstract}

\section{Keywords}

Accommodations, Neurodiversity, Volunteer Training, Inclusion

\section{Introduction}

There are indisputable benefits that come from children playing sports while growing up; children's cognitive, academic, social, and physical skills are all positively influenced by their involvement in sports programs (Bartko \& Eccles, 
2003; Eime et al., 2013; Pate et al., 2000; Singh et al., 2012). Relationship building skills, teamwork, self-confidence, and improved cognitive abilities are a few examples of benefits that are taught through sports. Additionally, there are various health behaviors, including healthy eating habits and lower levels of substance abuse, that have been shown to be benefitted by sports participation (Pate et al., 2000).

The majority of the literature examining the health impact of sport includes primarily typically developing children, with a gap of focus on children with disability who are an integral part of every community. Eighteen percent of children in the United States have some type of disability or chronic condition (Murphy \& Carbone, 2008). The disability not only impacts the individual but has significant impacts on the lives of the families and friends of these children in a variety of ways.

Rosenbaum and Gorter (2012) summed up the literature related to the importance of incorporating children with disabilities and their families using "f-words". They highlight the importance of moving away from associating the word "fix" to childhood disabilities but towards connecting the concepts of "function", "family", "fitness", "fun", "friends", and "future". This emphasizes the positive impact sport can play in this context, and the responsibility to approach these scenarios without a "fix" mentality. Through sports, function can improve; for example, a child learns teamwork and how to play a role in a large group. In addition, families are able to connect to other families with similar situations and interests and share a common context of pride to watch their children improve (Rosenbaum \& Gorter, 2012). Physical activity is essential for health in this population, which can easily be neglected and overlooked because of the complexity of participation (Pate et al., 2000; Rimmer \& Rowland, 2008). Sports provide an opportunity to have fun with peers and connect around a common goal. Sport is a ripe context to implement Rosenbaum and Gorter's (2012) movement towards positive integration of children with special needs and their families and away from the "fix" mentality.

Participation in sports programs is often driven by family. The value added to a family's quality of life will likely influence longevity of participation but this can be more complex overall for families with a child with disabilities for a multitude of reasons (Purcell, Turnbull, \& Jackson, 2006). The Beach Center Family Quality of Life scale has identified five domains that contribute to family quality of life: physical/material well-being; emotional well-being; parenting; family interaction; and disability-related supports (Park et al., 2003). Children's athletic participation positively affects families' overall quality of life (Rosenbaum \& Gorter, 2012), but the specifics, including challenges, barriers, and how to overcome them, are less understood.

Disability in and of itself is complex, but many children have multiple disabilities or domains of development that are affected by their disabilities, and thus affect their quality of life. Child and developmental disabilities affect behavioral, neurological, physical, social, and emotional domains (Halfon et al., 2012). Dis- 
parities in access, quality of health care, and family quality of life among children with varying disabilities were found for those with multiple disabilities (Cheak-Zamora \& Thullen, 2017). The domains of quality of life affected remain the same for these families; they are just more profoundly affected by the complexity and management of multiple disabilities (Petry, Maes, \& Vlaskamp, 2005).

Given the complexity for families of children with disabilities to participate in sports programs, the experience for their child matters. Sports programs that cater to children with disabilities understand that more people are needed to support participants. While this is positive overall, less is known about the training and role of coaches and volunteers in supporting children with disabilities in a sports setting. Shields and Synnot (2016) addressed this question by interviewing parents of children with disabilities in sports and identified several themes related to barriers and facilitators to a positive experience in sport program participation. One major theme was the people; the people leading and interacting with their children make the difference. Thus, volunteers and coaches in these programs have both a significant opportunity and a significant responsibility. Negative experiences for participants and their families may influence continued participation, performance, enjoyment, and overall success (Jorgensen, McSheehan, \& Sonnenmeier, 2007; Ohrberg, 2013; Bruce, Harman, \& Baker, 2000).

The purpose of this study was to explore family experiences and expectations in sport programs for children with disabilities. Specifically, asking parents of the participants' questions related to benefits for the families and what areas could be improved upon to facilitate a better experience for the participants and their families.

\section{Methods}

This study took place using a convenience sample of volunteer participants. The survey was sent to youth leagues that cater to children with disabilities. Parents filled out surveys and were included if they had at least one child with a self-disclosed disability that participated in a youth sport setting. This research design was approved by the University's Institutional Review Board. The variables of interest included quality of life (pediatric and family) as well as discussion of experiences in youth sport leagues serving individuals with disabilities.

\subsection{Measures}

The parent questionnaire included the Pediatric Quality of Life General Core, General Well-Being Inventories (Varni, Seid, \& Rode, 1999), and the Family Quality of Life Survey (Park et al., 2003). This Pediatric Quality of Life Generic Core Scale measured parent perceptions of their child's quality of life in terms of physical functioning, emotional functioning, social functioning, and school functioning, and a total score was computed from those four subscales. The Pediatric Quality of Life General Well-Being Scale, measured the child's general 
well-being. The Family Quality of Life Survey measured family interaction, parenting, emotional well-being, physical well-being, and disability support. Additionally, open-ended questions addressed topics including families' motivation to participate in sport programs, their expectations of the programs, coaches, and volunteers, their access to sports programs, the unique needs of their child, and their observations of positive facilitators and negative barriers to both their and their child's experiences.

Surveys were presented in a Qualtics ${ }^{\mathrm{XM}}$ format and were distributed through listservs, Facebook groups, and by directly contacting sports programs.

\subsection{Data Analysis}

The parent respondents were categorized into disability groups; child with one diagnosed disability, and child with multiple diagnosed disabilities. The quality of life questionnaires was analyzed with a multivariate ANOVA (MANOVA) across groups (1 disability (OD); 2 or more disabilities (MD)). For the family quality of life scale, a MANOVA was run to determine the significance of the disability groups among family interaction, parenting, emotional well-being, physical well-being and disability support. Univariate tests were reported to determine between subject effects on the family quality of life data. Additionally, for the pediatric quality of life measures, a MANOVA was performed for total quality of life scores and for the general well-being scores across number of disability groups. Univariate analysis was reported with significance level set at $p<$ 0.05 .

The open-ended questions of the surveys were exported and coded to identify themes. Once the themes were determined, the responses were then recoded into theme categories.

\section{Results}

\subsection{Participants}

Participants were identified as any parent of a child with disabilities who has participated in a special needs youth sports program at some point $(n=56)$. Of the parent participants, fifty-one respondents had received a bachelor's degree or higher. Household income was greater than $\$ 100,000$ for 26 of the families and less than $\$ 50,000$ for 12 families. Additionally, 43 had a family structure which consisted of two biological parents, 9 were single parents, and the remaining 4 were either blended families, adoptive parents, or same-sex parents. Additional demographics related to the child are in Table 1.

\subsection{Quality of Life}

For Family Quality of Life Inventory, the MANOVA showed a significant group effect $(F(5,50)=3.045, p=0.018)$, with the MD group having lower Quality of Life scores than the OD group. Univariate analysis showed significant group effects for emotional well-being $\left(\mathrm{F}(1,54)=8.183, p=0.006 ; \mathrm{M}_{\mathrm{OD}}=16.34 \pm 2.22\right.$; 
Table 1. Demographic information of participants.

\begin{tabular}{|c|c|c|c|}
\hline Sports* & No. & Disability (abbreviation) & No. \\
\hline Soccer & 38 & Trisomy 21/Down Syndrome (DS) & 3 \\
\hline Swim & 19 & Autism Spectrum Disorders (ASD) & 34 \\
\hline Baseball (+T-Ball + Softball) & 17 & Sensory Processing Disorders (SPD) & 8 \\
\hline Basketball & 15 & Developmental Delay (DD) & 2 \\
\hline Track (+Running) & 11 & Attention-Deficit Disorders (ADHD) & 19 \\
\hline Karate/Taekwondo & 9 & Obsessive Compulsive Disorders (OCD) & 2 \\
\hline Gymnastics/Dance/Cheer & 8 & Anxiety & 4 \\
\hline Football & 5 & Intellectual Disability (ID) & 8 \\
\hline Tennis & 5 & Apraxia & 3 \\
\hline Cycling & 4 & Cerebral Palsy (CP) & 3 \\
\hline Horseback Riding & 4 & Language Disorders (LD) & 2 \\
\hline Bowling & 3 & Hearing Impairment & 3 \\
\hline $\begin{array}{l}\text { Other (ice skating, skiing, } \\
\text { hockey, golf, Frisbee, } \\
\text { dodgeball, kickball, bocce) } \\
\text { ^23 participated in Special } \\
\text { Olympic programs }\end{array}$ & 12 & $\begin{array}{c}\text { Epilepsy } \\
\text { Other disorders (Cord Syndrome, } \\
\text { Rhett's Syndrome, Tetrasomy X, } \\
\text { eating disorder, Brain Injury, } \\
\text { Kleefstra syndrome, Prader Willi Syndrome) }\end{array}$ & 7 \\
\hline $\begin{array}{r}\text { Ages } 6 \text { - } 18 \\
32 \text { identified one disa }\end{array}$ & 11.9 & $\begin{array}{l}\text { yrs); } 42 \text { males, } 14 \text { females; } \\
4 \text { identified multiple disabilities (MD) }\end{array}$ & \\
\hline
\end{tabular}

$\left.\mathrm{M}_{\mathrm{MD}}=14.67 \pm 2.10\right)$ and physical well-being $\left(\mathrm{F}(1,54)=10.878, p=0.002 ; \mathrm{M}_{\mathrm{OD}}=\right.$ $\left.20.56 \pm 2.96 ; \mathrm{M}_{\mathrm{MD}}=18.13 \pm 2.40\right)$. Subscales of family interaction, parenting and disability support did not show significant differences across groups $(p<0.05)$. These results suggest that the family unit shows lower levels of physical and emotional well-being when raising a child with multiple disabilities.

For Pediatric Quality of Life Inventory, the MANOVA showed a significant group effect $(\mathrm{F}(2,50)=4.151, p=0.021)$. Univariate analysis showed there was a significant group effect for well-being $\left(\mathrm{F}(1,51)=8.469, p=0.005 ; \mathrm{M}_{\mathrm{OD}}=83.39 \pm\right.$ $\left.11.93 ; \mathrm{M}_{\mathrm{MD}}=72.73 \pm 14.70\right)$, there was no significant differences between disability groups for total score $(p<0.05)$ which included physical functioning, emotional functioning, social functioning, and school functioning subscales. Thus, quality of life across these subscales did not differ for individuals with multiple disabilities.

\subsection{Motivations/Expectations}

In order to learn more about why parents signed their children up for special needs sports programs, several open-ended questions asked about their motivation, as well as their expectations. When parents were asked what their motivation was to seek out a sport experience for their child they focused around ex- 
pectations for their specific child's needs in an environment that would also give them the same experiences as typically developing peers (e.g. socialization, physical activity, and emotional benefits).

"To have access to the same opportunities as his peers and for socialization, learning to play as a teammate, learning to respect authority" (7 yr old male, $A D H D /$ hearing loss)

"The child who has participated needs both exposure to social situations and physical activity in an environment where the goal is to teach." (10 yr old male, $A S D, A D H D$ )

"To have him feel proud of himself." (9 yr old male $A S D$ )

Parents were also asked about their expectations of their families' involvement in sports programs which included skill development or overall physical improvement; enjoyment/fun; social development; adequately equipped/trained coaches and volunteers; inclusive environment of respect; and challenge their child. It was clear that while parents had expectations, they were tampered with the understanding that it was not an easy task and so effort in this direction was valuable with volunteers and coach's efforts appreciated.

"To teach the sport, but take into account a child's specific needs." (6 yr old male, $A S D$ )

"That they are run well. Committed volunteers, with goals for the child to work on during a specific time frame." (13 yr old female, Apraxia of speech, $I D)$

"The staff be attentive, patient, creative and enthusiastic. That staff on the team see my child/ren as an individual and not just somebody with "xyz" diagnosis." (8 yr old male, $A S D, I D, A D H D$ )

\subsection{Access}

Parents were asked about access to sports programs that cater to children with disabilities. Several families found access to these programs relatively easily but several also found it challenging or were unable to find programs that served their children. For those that found it a challenge it was often related to where they lived and thought more metropolitan areas had more options. This difficulty in identifying opportunities and desire to find programs to serve their children was further exemplified by how far they had to travel to participate. We specifically gave them categories of how far they traveled for programs with $71 \%$ traveling under 30 minutes and $29 \%$ traveling 45 minutes or more to get access to these programs.

Parents were asked about why they stopped participation and common reasons included: logistical conflicts such as scheduling, location, or finances; child lost interest; or skill level was too easy or too difficult. However, some reasons directly related to the child's needs played a role for many as well.

"Basketball was too loud for sensory processing issues and my kids' motor 
skills made basketball too difficult. Also, their teammates made fun of them for not being good at it." (7 yr old male, $S P D)$

"He was kicked out for 'bad behavior'." (10 yr old male, $A S D)$

\subsection{Specific Needs of Participants}

As previously mentioned, the programs studied are oriented to focus on the specific population of children with disabilities so parental open-ended questions were included to ask about the children's needs and the effect of those needs. When asked about what their child's unique needs were, compared to a typically developing child, parent's answers fell into three themes including: difficulty following instructions; physical or communicative limitations; and sensory and social difficulties.

"Lack of overall awareness. Unable to follow instructions as well as [neurotypical] children his age." (6 yr old male, $A S D$ )

"Needs activities broken down into steps, notice of transitions, redirection." (6 yr old male, $A S D, A D H D$ )

"Easily dysregulated. Speech difficult to understand. Developmentally much younger in all areas." (14 yr old female, ASD, ID, Apraxia of speech)

"Lack of focus, coordination, understanding skills and rules as needed" (10 yr old male, $A S D, S P D)$

${ }^{*}$ It should be noted that while parent's described the unique needs of their child, the overlap in needs across disabilities was remarkable. This is important to keep in mind as we continue to not only look at experiences but consider take away points for implementation and training. ${ }^{* *}$

In tandem with parents identifying unique needs of their children, we also specifically asked about what instruction type helps to facilitate a positive experience for their child. Themes identified from parents' responses described different aspects of instruction including: how the tone, content and type of instruction matters; how beneficial descriptions include the terms positive and encouraging or gentle, calm, and understanding; and how varied cues are effective when structured and clear, and when they incorporate visuals.

"Positive reinforcement, step-by-step directions, participating with my child." (10 yr old male, $A S D$ )

"Peer models with intentional leadership of the coaches." (6 yr old male, $A S D, S P D)$

"She enjoys consistency and instructors that are calm but also funny and playful." (14 yr old female, ASD, ID, Apraxia)

"Demonstrative instruction with a visual supports works really well." (8 yr old male, $A S D$, Anxiety, $A D H D$ )

\subsection{Volunteer's Role}

In order to examine the impact volunteers have, parents were asked about vo- 
lunteers help in facilitating participation, and whether volunteer training is sufficient. Their responses fell into themes related to tone, content, and knowledge of working with disabilities and how to be inclusive.

"Help break the motor planning into smaller, simpler steps and helps keeping the interaction fun." (13 yr old female, Apraxia, ID)

"Providing constructive criticism where needed and praise as appropriate." (16 yr old male, $S P D$ )

"Being educated with people with disabilities to know how to interact with them." (16 yr old male, DS, ASD)

There were several responses that we would categorize as ways volunteers do not facilitate participation.

"Sometimes volunteers are 'too nice' and then they end up just talking instead of doing the activity or sometimes feed into anxiety instead of being in control of the situation." (14 yr old male, $A S D$ )

"[Volunteers] make my son feel like he's an object of pity and then he wants to quit. So anything that involves volunteers is now a non-starter for us." (11 yr old male, $A S D$ )

When asked if volunteers were appropriately trained to be able to positively facilitate their child's participation, many parents said they did not think they were, but acknowledged that they appreciated the volunteers being there and trying. Many suggested ways to improve training including increased communication with parents to help facilitate positive participation and the unique needs of their child.

\subsection{Positive Experiences}

Parents were asked to describe a specific positive and negative experience that they had at some point during their child's involvement. The themes identified from responses regarding positive experiences consisted of experiences involving happiness and encouragement; their child feeling accomplished; relationships formed with coaches and volunteers; a time their child was challenged; and social experiences.

"Seeing my son run toward me excitedly after he scored a goal in a drill and then giving me a big hug!" (7 yr old male, $A S D$ )

"My son is happier when he leaves than when he arrives." (8 yr old male, $C P$ )

\subsection{Negative Experiences}

When parents were asked about negative experiences, the themes identified were related to setting and program logistics; lack of constructive coaching and volunteer knowledge; bullying for other participants; and lack of their child's participation overall. 
"Once we had different teachers each week with my child. He really takes a while to warm up to someone so that didn't help him." (10 yr old male, $A S D, D D)$

"Not enough volunteers/volunteers didn't know my son's specific needs." (10 yr old male, $A S D$ )

"We had a soccer coach who was only interested in winning... Child barely got to play" (6yr old female, TBI)

"My son was discouraged, made fun of, gave up, and misbehaved" (10 yr old male, $A S D$ )

"When he didn't want to participate, volunteers just distanced themselves." (14 yr old male, $A S D$ )

"Volunteers were in control of the situation. They were nice, but also firm about what was going to take place. Felt very safe." (14 yr old male, ASD)

\section{Discussion}

The purpose of this study was to explore the perspectives of parents related to special needs youth sport. The goal was to learn more about the experiences and expectations of the families of children with disabilities who have participated in sport programs. The results from the current study indicated important themes in the areas of familial quality of life, how motivations and expectations from parents could influence volunteers, how lack of access and awareness could be limiting to participation, discrepancies in how best to serve the unique needs of the children, how volunteers are most effective, and communication between parents and coaches/volunteers.

\subsection{Quality of Life}

The results of the Family Quality of Life scale (Park et al., 2003) from the current study found that the families of children with one disability had significantly higher mean scores for emotional well-being and physical well-being, compared to the families of children with multiple disabilities. Research has already identified that participation in adaptive sport can positively impact overall family quality of life (Zabriskie, Lundberg, \& Groff, 2005). Research had also identified that the same domains of well-being (i.e. physical, emotional, social, material, support) could be used to measure familial quality of life in cases of one disability and multiple disability (Petry, Maes, \& Vlaskamp, 2005). The current study examined children who all participated in sport but looked at the specific subcategories of familial quality of life to determine that emotional and physical well-being were affected by number of disability but family interaction, parenting and disability support were not.

The current study also found that the group of children with one disability had a significantly higher mean score than the group of children with multiple disabilities for general well-being on the Pediatric Quality of Life Inventory (Varni et al., 1999). This indicates that when the child has more than one disa- 
bility, it negatively affects general well-being as opposed to the child only having one disability. Research states that sport participation impacts the child's overall well-being (Yazicioglu, Yavuz, Goktepe, \& Tan, 2012). However, this current study did not look at the influence of sport, given that all participants participated in sports. Instead, it looked at how the number of disabilities and comorbidity affects well-being when sports are already a part of the child's life. It built upon the Cheak-Zamora and Thullen (2017) study that found that there are disparities in health care quality based upon number of disabilities. The current study found that there are additional disparities that exist in child well-being and familial emotional and physical well-being due to the number of disabilities.

\subsection{Motivation and Expectations}

When parents were asked about what they expect from a sports program, the results showed that parents discussed expecting tolerance, respect, and inclusivity from a league. These are things that parents of typically developing children may not have to worry about to the same extent, given that social inclusion is an identified problem in disability populations specifically (Purcell et al., 2006; McConkey, Mullan, \& Addis, 2012). McConkey, Mullan, and Addis (2012) found that inclusion is an area that does not receive enough focus among children with ASD and found that an intervention, in which volunteers were better informed, yielded improvements in attitude and knowledge. The results from this study indicate that parents want to see inclusion and previous research shows that training can be implemented to better prepare volunteers to serve this purpose (Ohrberg, 2013; McConkey et al., 2012). Increasing training to improve volunteer knowledge and preparedness can lessen the social distance, or the discomfort someone feels interacting with a person with whom they are unfamiliar, that may have previously existed (Ouellette-Kuntz, Burge, Brown, \& Aresenault, 2010). Additionally, parents spoke about expecting adequately equipped coaches and volunteers; while any parent might want a competent coach for their child to look up to, the definition of adequately equipped can vary among the context of this population given the unique needs of the child (Ohrberg, 2013). In fact, according to the WHO report on Disability and Health (World Health Organization, 2018), people with disabilities are twice as likely to report that their needs are not met due to inadequate skill level of the provider. The significance of the role of volunteers and coaches in these programs was highlighted by the fact that most parents referenced volunteers and coaches as having made an impact, despite them not being referenced in the question, when asked about whether the program met their expectations. Ohrberg (2013) emphasized the importance of training coaches and volunteers in order for them to effectively meet the needs of participants and their families.

Parents identified fun and social development as two of their expectations for their child's participation in sports. This coincides with the research that supports that increased social participation is important for this population regardless of a child's ability, skill, age, or gender (Bult et al., 2011). Additionally, par- 
ents discussed expecting to see their child make improvements and highlighted a lack of communication between parents and volunteers/coaches around these expectations.

\subsection{Access}

The results of the current study also indicate a significant need to increase the access that the families of children with special needs have in relation to available and sufficient sports programs for their children. According to the WHO (World Health Organization, 2018) fact sheet on disability and health, a major barrier to families with special needs is the limited availability of services. The results from this study indicated that location matters. Almost half of respondents indicated a difficulty of finding access, and this shows that there is a need to increase awareness of these programs and increase access to these types of experiences/programs. This coincides with previous research that supports the social model, or the idea that disability is caused by societal barriers, which explains that these programs are more of a right than an extra option and that access should be offered to all groups (Lord \& Stein, 2009; Soffer \& Almog-Bar, 2016). The previous research argues that the social model should be used to view special needs youth sport, but the current study demonstrates that there is an increased need to utilize this view. It does bring up the question though, of whether the issue is the number of programs in existence that cater to special needs families or whether it is the lack of awareness of the aforementioned programs.

\subsection{Specific Needs of Participants}

Children with special needs who participate in sport are inevitably going to have unique needs that affect their participation in sport. However, it was important to investigate how and when these needs become a barrier to their overall experience since these needs are what primarily differentiate between sports programs for typically developing children and those with special needs. A majority of parents responded that their child's unique needs were either very limiting or at least somewhat limiting in their child's participation in sports programs. This highlights a need for programs to make adjustments in order to better suit the child's individual needs and in an effort to minimize these hindrances (Lord \& Stein, 2009; Soffer \& Almog-Bar, 2016). Interestingly, across age and disability, the unique needs of children were rather simple: sensory needs, structured clear instructions, visual demonstration, and safe and non-judgmental spaces/environment.

Looking further into the unique needs that parents identified though, there are some that will not be resolved by making adjustments to a program, including certain physical limitations. Physical barriers are one of the main identified limitations to the health of people with disabilities. However, there are also needs for which adjustments can be made. Sensory processing issues are quite 
common among children with disabilities; for example, it is estimated that 60 to $70 \%$ of children with ASD are affected by sensory issues (Adamson, O'Hare, \& Graham, 2006). In the current study, ASD was the most common diagnosis, though many of the other diagnoses are also affected by sensory issues. In this sports context, there are sensory adjustments that could be made to help lessen anxiety-stimulating environments or instruction styles that could be altered to better cater to the child's learning needs. Results from the current study, regarding the most effective instruction type, show that intentionally using an encouraging yet calm tone, incorporating demonstrations or one-on-one time, and keeping the content interesting but clear and to the point was the most motivating. Providing volunteers with instructions regarding these types of cues could potentially help this population's unique needs and limit the barriers that might otherwise result.

Parents expressed that the opportunity to provide feedback was important. Additionally, the suggestions for improvement that came up, in response to multiple questions, were to communicate more with parents; for example, meeting with the caretaker to get a better grasp on the child's needs prior to starting the league would help. Passing this information on to all coaches and volunteers would then help prepare them to best serve the unique needs of each participant.

\subsection{Volunteer Role}

In continuing the discussion of communication between parents and volunteers within the sport program, sharing information about the types of instruction that works best and the ways in which volunteers positively facilitate participation could be helpful. Research shows that a volunteer's perception of disability significantly influences the child (Bruce et al., 2000). If volunteers have more accurate expectations for the children, and believe in their abilities, they can utilize the results of the current study by incorporating the most effective type of instruction to most beneficially facilitate the child's participation. Additionally, this is supported by the responses from the parents who think volunteers are meaningful but that more appropriate training and increased communication could improve their contribution. More information communicated between parents and volunteers would be appreciated by both groups involved and could decrease the existing social distance.

\subsection{Experiences}

Parents described their positive experiences as times that involved happiness, laughter, and encouragement in a supportive environment. These findings are also seen in research on typically developing sports, where mood increases and improved self-esteem are also seen as results of sports participation (Eime et al., 2013). Additionally, building relationships with volunteers/coaches and other kids/families was a positive experience. Relationship building skills and team- 
work are also seen as benefits of sport among typically developing populations. Parents also described times when their child was challenged as a positive and this is something that could result more often if volunteers had increased knowledge as to the capabilities of the children with whom they are working. Research has identified that perceived competence is shown to significantly influence a child's performance (Jorgensen et al., 2007). Previous literature supports this notion of increased preparation in terms of increasing volunteer knowledge and finds that more positive interactions result (Ouellette-Kuntz et al., 2010).

In terms of bad experiences from the parental perspective, some of the themes identified were unavoidable. The child's lack of participation was something that can be unavoidable given that sometimes certain sports are not going to be liked by certain children. This is not unique to children with special needs given that children in typically developing sports are also likely to quit a league or not participate due to a dislike of the specific sport (Wiersma, 2000). Some aspects of a setting, for example the weather, are unavoidable conflicts that are also out of the league's control. Additionally, negative influences from other participants, including bullying and mean comments, were things that cannot be completely controlled by the league. This could mean there is a need for increased supervision or the enforcement of rules, but ultimately the behavior of other participants is an external factor that is out of the league's control.

There are some negative experiences that can be adjusted for though, like complaints about the league structure. Some of the structures of the programs could be altered to more positively accommodate the majority of the participants. Additionally, the remaining negative experience theme, a lack of either volunteer knowledge or constructive coaching, was something that is more fixable. Informing volunteers and coaches more adequately about how to best serve a child's needs could negate some of the bad experiences parents have had. Increasing knowledge and preparation also would decrease the social distance, which would therefore allow volunteers to become more comfortable interacting with children with disabilities (Fichten, Schipper, \& Cutler, 2005).

\subsection{Limitations/Future Studies}

The data gathered from this study is limited in the way in which it was collected. There was convenience sampling given that, even though we attempted to utilize listservs, many of the leagues contacted for both responses to the questionnaires were often local leagues, leagues with personal connections, or referred from a familiar league. There was also no specification to a specific sport or league type (i.e. individual versus team sports) nor was there a clarification on what type of special need or disability (i.e. intellectual versus physical). This was done in order to gather as much data as possible; however, future studies could explore how the results would differ if a certain sport was studied or a certain type of special need. Another limitation was the number of questionnaires that were started but not completed which could lead to a response bias based on the length of questionnaires and time available to respond. The participants who 
completed the entire questionnaire and fully elaborated on their responses were likely people that felt very strongly about the subject matter. Parents may have also decided not to do the questionnaire if they did not have the time to allocate. Additionally, all the questionnaires from this study were distributed electronically so it limited any families who do not have access to the internet from completing the study. Future studies would be benefitted by gathering more participants from a wider range of locations to get a fuller sense of this subject.

\section{Practical Applications}

The results from this study are indicative of areas in which the gaps surrounding expectations and perspectives of the role of volunteers can be easily addressed, specifically, communication of unique needs of the child to volunteers and coaches as well as consistent updating. There are aspects of volunteer training that could be more universal such as type of instruction, expectations, and environmental factors. In addition, improving aspects such as the organizational structure of sports programs and increasing accessibility of experiences are also applications of this study that could have a positive effect. This is in line with what we see in the literature and so it is imperative organizations and programs that hear this need. Volunteers play an integral role in the quality of sports programs/experiences that cater to children with disabilities and training both coaches and volunteers should not be overlooked (Ohrberg, 2013; Bruce, Harman, \& Baker, 2000). Unintentional decisions to coddle or reduce challenge in participants often occur because of a lack of knowledge of what is an appropriate challenge to a child in a sport setting. Volunteers and coaches need to be equipped and prepared to facilitate positive interactions for participants with special needs (Ouellette-Kuntz et al., 2010; Fichten et al., 2005). Table 2 includes some broad advice for sports programs to consider when serving children with disabilities and their families.

\section{Acknowledgements}

We would like to thank the volunteers of this study and the many sport leagues that support children with disabilities and distributed the opportunity to participate in this study to their families.

Table 2. Tips when working with children with disabilities.

\footnotetext{
Volunteers should try to make eye contact and should get on the child's level

If child does not verbally respond or does not maintain eye contact, volunteers should keep instructing and interacting-don't take it as a reason to stop trying to communicate

Leagues should be upfront and forthcoming about their set-up and structure to accurately set expectations for both volunteers and parents

Volunteers should give specific feedback and specific praise to children

Volunteers should vary the types of instruction their giving; i.e. try demonstrations, give both visual and audio cues
} 


\section{Conflicts of Interest}

The authors declare no conflicts of interest regarding the publication of this paper.

\section{References}

Adamson, A., O’Hare, A., \& Graham, C. (2006). Impairments in Sensory Modulation in Children with Autistic Spectrum Disorder. British Journal of Occupational Therapy, 69, 357-364. https://doi.org/10.1177/030802260606900803

Bartko, W. T., \& Eccles, J. S. (2003). Adolescent Participation in Structured and Unstructured Activities: A Person-Oriented Analysis. Journal of Youth and Adolescence, 32, 233-241. https://doi.org/10.1023/A:1023056425648

Bruce, A. J., Harman, M. J., \& Baker, N. A. (2000). Anticipated Social Contact with Persons in Wheelchairs: Age and Gender Differences. Advances in Psychology Research, 1, 219-228.

Bult, M. K., Verschuren, O., Jongmans, M. J., Lindeman, E., \& Ketelaar, M. (2011). What Influences Participation in Leisure Activities of Children and Youth with Physical Disabilities? A Systematic Review. Research in Developmental Disabilities, 32, 1521-1529. https://doi.org/10.1016/j.ridd.2011.01.045

Cheak-Zamora, N. C., \& Thullen, M. (2017). Disparities in Quality and Access to Care for Children with Developmental Disabilities and Multiple Health Conditions. Maternal and Child Health Journal, 21, 36-44. https://doi.org/10.1007/s10995-016-2091-0

Eime, R. M., Young, J. A., Harvey, J. T., Charity, M. J., \& Payne, W. R. (2013). A Systematic Review of the Psychological and Social Benefits of Participation in Sport for Children and Adolescents: Informing Development of a Conceptual Model of Health through Sport. International Journal of Behavioral Nutrition and Physical Activity, 10, 98. https://doi.org/10.1186/1479-5868-10-98

Fichten, C. S., Schipper, F., \& Cutler, N. (2005). Does Volunteering with Children Affect Attitudes toward Adults with Disabilities? A Prospective Study of Unequal Contact. Rehabilitation Psychology, 50, 164-173. https://doi.org/10.1037/0090-5550.50.2.164

Halfon, N., Houtrow, A., Larson, K., \& Newacheck, P. W. (2012). The Changing Landscape of Disability in Childhood. The Future of Children, 22, 13-42. https://doi.org/10.1353/foc.2012.0004

Jorgensen, C. M., McSheehan, M., \& Sonnenmeier, R. M. (2007). Presumed Competence Reflected in the Educational Programs of Students with IDD before and after the Beyond Access Professional Development Intervention. Journal of Intellectual and Developmental Disability, 32, 248-262. https://doi.org/10.1080/13668250701704238

Lord, J. E., \& Stein, M. A. (2009). Social Rights and the Relational Value of the Rights to Participate in Sport, Recreation, and Play. Boston University International Law Journal, 27, 249.

McConkey, R., Mullan, A., \& Addis, J. (2012). Promoting the Social Inclusion of Children with Autism Spectrum Disorders in Community Groups. Early Child Development and Care, 182, 827-835. https://doi.org/10.1080/03004430.2011.586128

Murphy, N. A., \& Carbone, P. S. (2008). Promoting the Participation of Children with Disabilities in Sports, Recreation, and Physical Activities. Pediatrics, 121, 1057-1061. https://doi.org/10.1542/peds.2008-0566

Ohrberg, N. J. (2013). Autism Spectrum Disorder and Youth Sports: The Role of the Sports Manager and Coach. Journal of Physical Education, Recreation \& Dance, 84, 
52-56. https://doi.org/10.1080/07303084.2013.838118

Ouellette-Kuntz, H., Burge, P., Brown, H. K., \& Arsenault, E. (2010). Public Attitudes towards Individuals with Intellectual Disabilities as Measured by the Concept of Social Distance. Journal of Applied Research in Intellectual Disabilities, 23, 132-142. https://doi.org/10.1111/j.1468-3148.2009.00514.x

Park, J., Hoffman, L., Marquis, J., Turnbull, A. P., Poston, D., Mannan, H., Nelson, L. L. et al. (2003). Toward Assessing Family Outcomes of Service Delivery: Validation of a Family Quality of Life Survey. Journal of Intellectual Disability Research, 47, 367-384. https://doi.org/10.1046/j.1365-2788.2003.00497.x

Pate, R. R., Trost, S. G., Levin, S., \& Dowda, M. (2000). Sports Participation and Health-Related Behaviors among US Youth. Archives of Pediatrics \& Adolescent Medicine, 154, 904-911. https://doi.org/10.1001/archpedi.154.9.904

Petry, K., Maes, B., \& Vlaskamp, C. (2005). Domains of Quality of Life of People with Profound Multiple Disabilities: The Perspective of Parents and Direct Support Staff. Journal of Applied Research in Intellectual Disabilities, 18, 35-46. https://doi.org/10.1111/j.1468-3148.2004.00209.x

Purcell, M. L., Turnbull, A., \& Jackson, C. W. (2006). Linking Early Childhood Inclusion and Family Quality of Life: Current Literature and Future Directions. Young Exceptional Children, 9, 10-19. https://doi.org/10.1177/109625060600900302

Rimmer, J. A., \& Rowland, J. L. (2008). Physical Activity for Youth with Disabilities: A Critical Need in an Underserved Population. Developmental Neurorehabilitation, 11, 141-148. https://doi.org/10.1080/17518420701688649

Rosenbaum, P., \& Gorter, J. W. (2012). The "F-Words" in Childhood Disability: I Swear This Is How We Should Think! Child: Care, Health and Development, 38, 457-463. https://doi.org/10.1111/j.1365-2214.2011.01338.x

Shields, N., \& Synnot, A. (2016). Perceived Barriers and Facilitators to Participation in Physical Activity for Children with Disability: A Qualitative Study. BMC Pediatrics, 16, Article No. 9. https://doi.org/10.1186/s12887-016-0544-7

Singh, A., Uijtdewilligen, L., Twisk, J. W., Van Mechelen, W., \& Chinapaw, M. J. (2012). Physical Activity and Performance at School: A Systematic Review of the Literature Including a Methodological Quality Assessment. Archives of Pediatrics \& Adolescent Medicine, 166, 49-55. https://doi.org/10.1001/archpediatrics.2011.716

Soffer, M., \& Almog-Bar, M. (2016). Therapy or Human Right? The Meaning of Recreation for Children and Youth with Disabilities in the "Krembo Wings" Youth Movement. Disability and Health Journal, 9, 399-405.

https://doi.org/10.1016/j.dhjo.2016.04.001

Varni, J., Seid, M., \& Rode, C. (1999). The PedsQL ${ }^{\mathrm{m}}$ : Measurement Model for the Pediatric Quality of Life Inventory. Medical Care, 37, 126-139. https://doi.org/10.1097/00005650-199902000-00003

Wiersma, L. D. (2000). Risks and Benefits of Youth Sport Specialization: Perspectives and Recommendations. Pediatric Exercise Science, 12, 13-22. https://doi.org/10.1123/pes.12.1.13

World Health Organization (2018). Disability and Health. https://www.who.int/news-room/fact-sheets/detail/disability-and-health

Yazicioglu, K., Yavuz, F., Goktepe, A. S., \& Tan, A. K. (2012). Influence of Adapted Sports on Quality of Life and Life Satisfaction in Sport Participants and Non-Sport Participants with Physical Disabilities. Disability and Health Journal, 5, 249-253.

https://doi.org/10.1016/j.dhjo.2012.05.003 
Zabriskie, R. B., Lundberg, N. R., \& Groff, D. G. (2005). Quality of Life and Identity: The Benefits of a Community-Based Therapeutic Recreation and Adaptive Sports Program. Therapeutic Recreation Journal, 39, 176-191. 